\title{
A Representação Social do Trabalho do Psicológo
}

The social representation of the Psychologist's work

Kátia Botelho Diamico Praça

Psicóloga. Mestre em

Psicologia Social.

Especialista em

Psiquiatria Social.

Professora do Curso de

Graduação em

Psicologia da

Universidade Gama Filho.

\section{Heliane Guimarães Vieites Novaes \\ Psicóloga. Mestre em Psicologia Social Especialista em Educação. Professora dos cursos de Psicologia e Pedagogia da Universidade Gama} Filho.

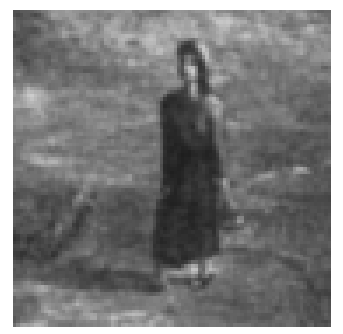

Resumo: $O$ presente trabalho apresenta um sumário dos principais resultados de uma pesquisa que teve como objetivo conhecer as representações sociais da Psicologia e do trabalho do psicólogo. Os sujeitos foram 375 estudantes do penúltimo ano de graduação dos cursos da área da saúde e que responderam a um questionário com cinco questões abertas e oito fechadas. Neste trabalho, analisaremos as respostas dadas a nove questões. Constatou-se que as representações acerca da Psicologia e do trabalho do psicólogo apontam para uma visão altamente subjetivista e individualista, em que as condições sociais, históricas e culturais presentes nas experiências subjetivas são excluídas. O estudo indica a urgência de uma reflexão sobre a responsabilidade social e ética do psicólogo.

Palavras-Chave: Psicologia, trabalho do psicólogo, representação social, responsabilidade social, ética.

Abstract: This work presents a summary of the main results of a research that aims to know the social representations of Psychology and the psychologist's work. The subjects were about 375 students of the graduation courses in the health ground of the University Gama Filho. They answered a questionaire with five opened questions and eight closed ones. In this work we'll analyse nine answers. We prove that representations about Psychology and the psychologist's work indicate a top personal and subjective vision where the social, historical and cultural conditions in the subjective practices are eliminated. The work indicates the psychologist's need of an essential reflection about his social responsibility and ethics.

Key Words: Psychology, the psychologist's practice, social representation, social responsibility, ethics.

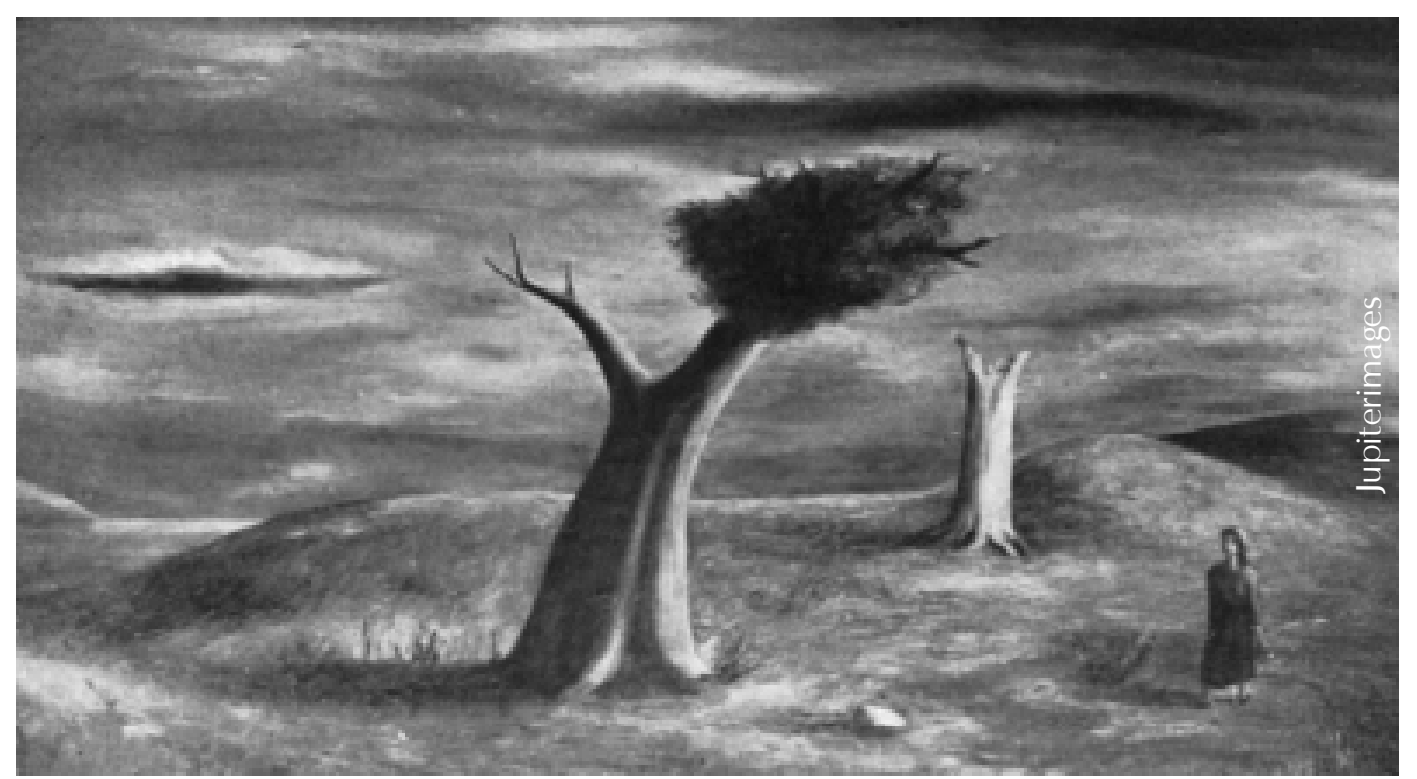

O presente trabalho apresenta um sumário dos principais resultados de uma pesquisa realizada em 1999, como disciplina do Curso de Graduação de Psicologia da Universidade Gama Filho, sobre a representação social da práxis do psicólogo. Os sujeitos da pesquisa foram 375 universitários do penúltimo ano de cursos de graduação da área da saúde de uma universidade da cidade do Rio de Janeiro.
Pensamos ser este veículo importante sob um duplo aspecto: por um lado, pela crescente e generalizada intervenção que leva em conta a importância da interdisciplinaridade, e, por outro, a consideração de algumas dificuldades no exercício profissional do psicólogo. Conforme mostram Bastos e Gomide, "as dificuldades no exercício profissional que têm intensidade de ocorrência mais elevada são as provocadas pela 
política socioeconômica do País e as relacionadas ao desconhecimento, por outros profissionais, da contribuição que o psicólogo pode oferecer" (1989, p.14).

Também Carvalho (1988) alerta que, por parte dos próprios profissionais da área, impera (ou pelo menos, na época, imperava) uma avaliação pessimista do exercício profissional, com baixa credibilidade da profissão junto à população e aos profissionais de outras áreas.

Por outro lado, vários estudos vêm interrogando o profissional que estamos formando, propondo reflexões cruciais acerca da Psicologia e do psicólogo, apontando principalmente para questões políticas e sociais pertinentes às análises e ações desse profissional, muitas vezes ausentes (Bastos, A. V. B., 1988; Bettoi, W. e Simão, L. M., 2000; Bock, A. M. B., 1997; Branco, M. T. C., 1999; Contini, M. L. J., 2000; Moura E. P. G., 1999).

Historicamente, sabe-se que a profissão de psicólogo surge ligada às demandas de um regime disciplinar de adequar, ajustar, adaptar. $\bigcirc$ psicólogo "aplicava testes" para selecionar "o funcionário certo para o lugar certo", para classificar o escolar numa turma que the fosse adequada, para treinar o operário, para programar a aprendizagem etc. Pensamos, como Figueiredo (1997), que essas funções ainda são importantes na definição da identidade profissional do psicólogo, evidenciando que a vinculação da Psicologia às demandas de um regime disciplinar estão presentes até hoje.

Recentemente, Bock (2000), através de uma pesquisa realizada entre os anos 1992 e 1997, com psicólogos registrados no Conselho Regional de São Paulo, mostrou que a maioria das respostas dadas pelos profissionais referentes à visão de homem, de mundo, de fenômeno psicológico e da própria prática profissional revelam, de forma predominante, uma concepção liberal de homem, onde se naturaliza o fenômeno psicológico, ou seja, o homem é pensado como possuidor de uma essência originária, que faria parte de uma "natureza". A autora também enfatiza a concepção do termo "social", que, praticamente, refere-se apenas à existência de outros homens. Conseqüentemente, não surpreende que, em relação à perspectiva sobre a prática profissional, questões sociopolíticas sejam ignoradas ou inexistentes para a grande maioria dos profissionais que participaram deste estudo.

Concordamos com Moura (1999) que, ao problematizar questões fundamentais a respeito da Psicologia e dos psicólogos que temos produzido, deixa patente a consagração de uma intervenção profissional voltada para a conformidade e o ajustamento do homem ao meio, o que denota a grande ausência da dimensão social na concepção da Psicologia sobre seu objeto de estudo. Ignoram-se, também, os processos de produção de subjetividade contemporâneos.

Também enfocando a questão da formação do psicólogo e sua identidade profissional, Contini nos diz que "A formação, hoje, via de regra, está calcada em um modelo conservador de promoção de saúde... sustentado por teorias que têm o seu foco voltado para a descrição dos comportamentos patológicos... Essa situação tem contribuído para uma consolidação da identidade do psicólogo marcada exclusivamente pelo seu caráter terapêutico, dificultando a construção de um outro profissional que possa atender diferentes situações, como as institucionais e comunitárias (p.53).

A partir dessas reflexões, temos como objetivo principal deste trabalho analisar até que ponto as representações sociais aqui encontradas refletem uma visão que inclui a dimensão político-social no saber-fazer do psicólogo, ou seja: o psicólogo é visto como um profissional crítico acerca das questões políticas e sociais presentes no contexto onde se dá sua intervenção, voltado para a produção de novas formas de relações na vida, ou é visto como um profissional comprometido com a adaptação social, com a legitimação de formas instituídas, hegemônicas de ser em nossa sociedade?

Entendemos o conceito de representação social através da concepção de Serge Moscovici, pois esta possibilita a compreensão de um objeto social a partir de representações que refletem a cultura e a sociedade na qual o sujeito está inserido, o que vai de encontro ao nosso propósito aqui. As representações sociais, para Moscovici, são "...o conjunto de conceitos, explicações e afirmações que se originam na vida diária, no curso de comunicações interindividuais " (1981, p.47). São entidades quase tangíveis, que se articulam e se cristalizam por meio de gestos, falas, encontros, de forma ininterrupta, no universo cotidiano, impregnando a maioria de nossas relações sociais.

Ao inaugurar uma nova perspectiva de investigação em Psicologia Social, Moscovici demonstra a inevitável indissociação entre indivíduo, grupo e sociedade na apreensão do saber cotidiano. Podese dizer que, a partir de seu estudo sobre a representação social da Psicanálise (1961), surge uma abordagem teórico-metodológica inédita, que trata da compreensão dos processos de construção e transformação das representações sociais produzidas e reproduzidas dentro de grupos
Auxiliares de pesquisa:

Alunos do Curso de Graduação em Psicologia da UGF

AngélicaMartins

Perdigão Gomes

Angélica Cecilia de Carvalho

Bruna dos Santos Ferraz

Caroline Carvalho Deniolo

Joselinda Silva Santana

Luciana Chagas

Pessoa de Mello

Luciana Ozório Lapa

Milena Azevedo Gomes de Magalhães

Roberto Carvalho Alves Filho Rosângela Simonetti Sabrina Venturini Ramos

Tatiane Braga Bellieny

Vanessa Alves Moraes 
sociais. Assim, a recuperação dos sujeitos como aqueles que constroem tanto o mundo, como a si próprios, através de suas atividades e relações com a sociedade, torna-se fundamental para a base de sua teoria. Importa, então, perceber a relação essencial entre o universal e o particular.

A teoria das representações sociais reside na idéia de que os sujeitos buscam explicações, criam teorias próprias sobre uma série infindável de assuntos que prendem a atenção e a curiosidade, demandando compreensão e pronunciamentos quotidianos a respeito de temas sociais contemporâneos como a escola, a moral, a religião, a política, a cultura, a saúde, a doença, a violência, a tecnologia, as desigualdades sociais, econômicas etc. Tais explicações não são simples opiniões, mas possuem uma lógica própria, baseada nas mais diferentes informações e julgamentos valorativos adquiridos por diferentes fontes, além de fundamentarem-se também em experiências pessoais e grupais.

Para maior entendimento da teoria, é importante destacarmos a existência de duas classes distintas de universo de pensamento: os universos consensuais e os reificados. Nos universos reificados, encontramos as ciências e o pensamento erudito em geral. Nos consensuais, viajam os pensamentos e idéias que, freqüentemente, tiveram origem nos universos reificados, mas foram reapropriados pelos demais integrantes da sociedade de uma forma particular, através de uma lógica diversa daquela em que se produzem os conhecimentos científicos, colaborando, portanto, para a existência das representações sociais. Portanto, representar algo não é simplesmente repeti-lo, mas, sim, reconstituí-lo, modificando-lhe o texto.

Ao recuperar a inter-relação do individual com o social e ver os sujeitos como capazes de oporemse ao que já está dado e inventado, resistindo aos modelos hegemônicos, abre-se espaço para as transformações e representações modificadas.

Importa, também, assinalar que as representações sociais, da forma aqui entendida, são criadas para possibilitar a comunicação entre sujeitos. São mediações sociais e permitem que saberes estranhos se tornem familiares. A construção imaginativa e simbólica do mundo ocorre na interseção entre conhecimentos prévios, tradicionais (já conhecidos, mas nunca completamente abandonados) e a necessidade de reformulá-los, dar-lhes nova roupagem, recriandoos e, dessa forma, introduzindo o novo. A construção das representações dá-se à medida que os sujeitos retornam suas memórias, suas tradições e experiências e mesclam esses antigos elementos aos novos, dando prosseguimento à produção do mundo de idéias e imagens que vivemos. O resultado das representações reificadas (inicialmente estranhas), amalgamadas com os conhecimentos prévios, é altamente criativo e inovador no seio da vida quotidiana. As representações sociais de objetos sociais são, assim, produtos do comportamento criador do homem. Segundo Moscovici, "O objeto está inscrito num contexto ativo, dinâmico, pois que é parcialmente concebido pela pessoa ou a coletividade como prolongamento de seu comportamento, e só existe para eles enquanto função dos meios e dos métodos que permitem conhecê-lo " (1978, p.52).

Importa, ainda, assinalarmos dois processos fundamentais nessa elaboração das representações sociais, a saber: a ancoragem e a objetivação.

A ancoragem diz respeito a um processo de trazer para categorias e imagens já conhecidas aquilo que ainda não está classificado e (ou) rotulado.

A objetivação reside no processo de transformar uma abstração em algo tangível, quase físico. Implica descobrir o aspecto icônico de uma idéia. Observa-se, então, que as representações sociais tratam de fornecer um enquadre que contextualiza os sistemas de categorização de uma sociedade. As classificações, dessa forma, não são constatações de fatos, mas encontram seu lugar em uma harmonia criada pelas representações. Quando o leigo diz que psicólogo é maluco, isso deve ser entendido a partir de uma rede de significações provenientes das representações sociais sobre o psicólogo.

\section{Metodologia}

Amostra: A amostra constou de 375 estudantes universitários do penúltimo ano de graduação de uma universidade da cidade do Rio de Janeiro, dos seguintes cursos: Psicologia, Nutrição, Enfermagem, Medicina, Fisioterapia, Biologia, Odontologia e Educação Física.

Instrumento: A partir da aplicação de um préteste, foi elaborado um questionário com cinco questões abertas e oito questões fechadas. No presente trabalho, analisaremos as respostas dadas a nove questões, a saber: 1- "Na sua opinião, o que é Psicologia?"(aberta), 2-“Na sua opinião, qual o principal objeto de estudo da Psicologia?"(fechada), 3- "Em que locais podemos encontrar psicólogos trabalhando?"(fechada), 4"Na sua opinião, qual é o principal objetivo do psicólogo em seu trabalho?"(fechada), 5- "Do que o psicólogo se utiliza em sua prática?"(fechada), 6- "Que características você atribuiria ao profissional de Psicologia?"(fechada), 7- "Você 
acredita que um trabalho psicológico produza bons resultados?"(aberta), 8- "Você buscaria algum serviço psicológico se sentisse necessidade?"(aberta) e 9- "Escolha a frase que mais se aproxima de seu pensamento acerca da Psicologia e do psicólogo"(fechada).

Procedimento: Na investigação para identificação do conteúdo das representações sociais da profissão do psicólogo, foi realizada uma análise de conteúdo, em função da qual as opiniões e comentários foram submetidos à análise temática baseada em um sistema de categorias. Com o propósito de análise, foram computadas as freqüências com que os vários conteúdos temáticos apareceram e, posteriormente, calculadas as percentagens de suas incidências. Realizou-se, também, uma análise comparativa entre as respostas dos estudantes de Psicologia e as respostas dos estudantes dos outros cursos. Cabe ressaltar que o cálculo de incidência das categorias teve como base o número de sujeitos. Foram criadas nove categorias, respectivamente, de acordo com as nove questões em análise, já citadas.

A primeira categoria foi "caracterização da Psicologia", tendo seis subcategorias: estudo do comportamento, estudo de fenômenos psicológicos, estudo da relação do homem com o social, estudo do ser humano, função assistencialista e promoção da saúde (tabela 1). A segunda categoria, denominada "objeto de estudo", tem como subcategorias: mente, alma, comportamento, inconsciente, subconsciente, consciência e subjetividade (tabela 2). A terceira categoria foi chamada "local de trabalho", abrangendo as subcategorias: condomínio, comunidades carentes, sindicatos, associações esportivas, clínica, escola, hospital, consultório, presídio, igreja, centro espírita e empresa (tabela 3). Na quarta categoria, "objetivo profissional", temos como subcategorias: tratar doenças dos nervos, ajudar as pessoas, promover saúde, melhorar a qualidade de vida, curar, mudar comportamentos e integrar-se às normas sociais (tabela 4). A quinta categoria, denominada "instrumentos do psicólogo", inclui as subcategorias: medicação, entrevistas, dinâmica de grupo, cristais, brinquedos, testes psicológicos, mapa astral, florais de bach, ouvir as pessoas e terapia de vidas passadas (tabela 5). A sexta categoria, "características do psicólogo" apresenta como subcategorias: cientista, observador, manipulador, honesto, maluco, charlatão, confiável, culto, equilibrado, problemático (tabela 6). A sétima categoria, "credibilidade no trabalho do psicólogo", e a oitava categoria, "busca de serviços psicológicos", têm, como subcategorias , sim, não e talvez. A nona categoria, "imagem da Psicologia e do psicólogo", apresenta as subcategorias: tenho amigos, psicólogo é maluco, de médico, psicólogo e louco, Psicologia é saúde, terapia é para rico, coisa de mulher, serviços supérfluos e não tem o que fazer.

\section{Análise e Discussão dos Resultados}

De acordo com a tabela 1, na categoria "caracterização da Psicologia", a maioria das respostas revela uma imagem da Psicologia como estudo do comportamento e de fenômenos psicológicos. Essa representação revela-se em expressões como: "a Psicologia estuda o comportamento humano e a mente humana", “...avalia os seres humanos nos seus aspectos psicológicos".

Ao que parece, a dita avaliação baseia-se em critérios de adequação ou não do homem e referese à dimensão comportamental, explicada, aí, como efeito de fenômenos puramente individuais e naturalizantes dos fenômenos psicológicos. Em outras palavras, o comportamento humano e os fenômenos psicológicos aparecem como fazendo parte de algo intrínseco ao homem, como uma essência que o caracterizaria. Dessa forma, excluise a dimensão histórica e social presente no individual. Ignora-se, assim, que o humano não é algo dado aprioristicamente, mas, sim, uma construção que se dá no processo dialético presente nas relações estabelecidas com outros.

Outro dado que deve ser ressaltado refere-se à subcategoria função assistencialista, revelando a representação da Psicologia como aquela que pode dar ajuda incondicional ao outro. Podemos notar isso a partir de declarações como: " a Psicologia ajuda nos problemas", "...resolve e compreende os problemas...", "cuida das pessoas", "ajuda no autoconhecimento", "ajuda a lidar com a vida", "ajuda em uma nova visão de mundo".

As subcategorias referentes aos fenômenos psicológicos e ao assistencialismo remetem ao que mostra Magalhães e Keller (2001), em estudo realizado sobre a escolha vocacional em Psicologia, na perspectiva de quem está ingressando no Curso de Graduação em Psicologia. Na pesquisa desses autores, a maior parte das declarações expressam o desejo de ajudar o outro associado a interesses por assuntos psicológicos (a mente humana, gênese da psiquê) e seu desenvolvimento. A ajuda ao outro, assim como no presente trabalho, implica mudança de visão de mundo e melhoria das relações com os outros e com a sociedade em geral.

Cabe observar a roupagem onipotente com que se veste a Psicologia e, conseqüentemente, aqueles que trabalham com ela. Ciência capaz de mudar, 
Kátia Botelho Diamico Praça \& Heliane Guimarães Vieites Novaes

melhorar, resolver a vida e as relações estabelecidas. Quanto poder!!! Não é por acaso que o profissional da área (e o estudante também) tem o estereótipo comum e antigo de "adivinhar o que os outros pensam", "tem bola de cristal" etc.

Bock, A. B. M., em estudo realizado entre 1992 e 1999, tendo como amostra psicólogos registrados no Conselho Regional de Psicologia de São Paulo, já mostrou como "os psicólogos evidenciam, em seus discursos, principalmente quando relatam seus trabalhos, uma noção onipotente da profissão e de si próprios como profissionais, acreditando que têm nas mãos a possibilidade de fazer do outro um homem feliz, de colocá-lo em movimento". Esse discurso, porém, é acompanhado da idéia de que "...mas o psicólogo não muda o homem, apenas contribui para que ele próprio se modifique". A autora alerta-nos para o fato de que, aí, "a onipotência se traveste de humildade" (2000, p.23).

É importante observar, neste ponto, a relação existente entre os universos reificados, representados aqui pela Psicologia, e os consensuais, isto é, a forma de apropriação das idéias e pensamentos ligados à Psicologia.

Na subcategoria estudo da relação do homem com o social, evidencia-se o percentual de 6,9\%, onde encontramos idéias como: "é a ciência que estuda a relação do homem com a sociedade", "é a ciência que integra o homem ao social", " procura adaptar o homem e melhorar suas relações com as outras pessoas". Cabe salientar, nessas respostas, a presença de uma noção dicotômica das relações do homem com a sociedade. O homem parece ser pensado como uma imanência independente do social e do cultural. Ao ignorar que a sociedade diz respeito a uma rede de significados simbólicos produzidos e reproduzidos pela atividade humana, que, ao produzir sua cultura e sua história, o homem produz a si mesmo, só resta mesmo pensá-lo como objeto a ser ajustado e adaptado a uma realidade social, vista como uma espécie de engrenagem, à parte de questões relativas à subjetividade.

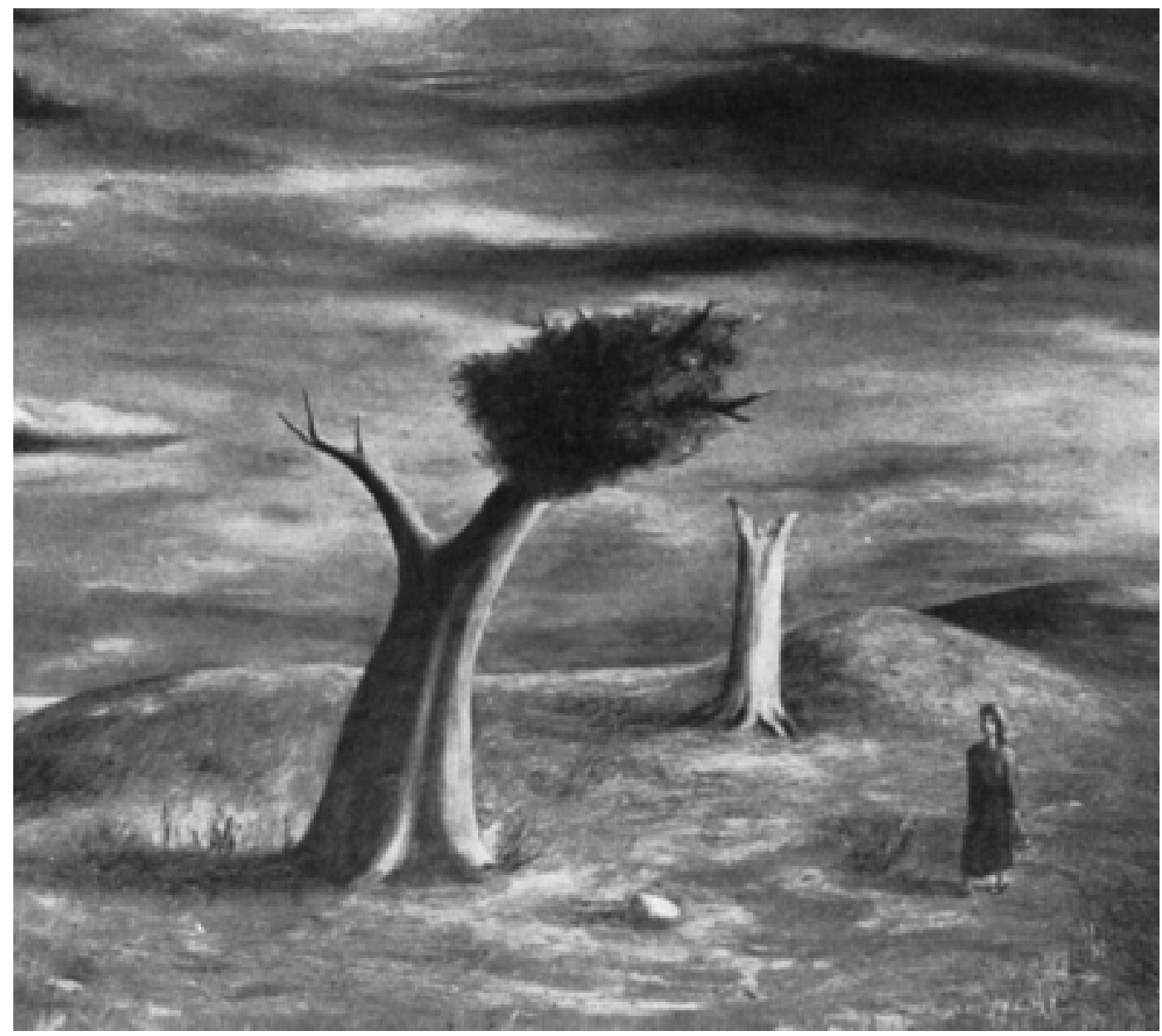


Tabela 1: "caracterização da Psicologia"

\begin{tabular}{|c|c|c|c|c|c|c|c|c|c|}
\hline & & $\begin{array}{l}\text { Estudo do } \\
\text { comporta- } \\
\text { mento }\end{array}$ & $\begin{array}{l}\text { estudo do } \\
\text { fenômeno } \\
\text { psicológico }\end{array}$ & $\begin{array}{l}\text { estudo } \\
\text { relação } \\
\text { homem/ } \\
\text { social }\end{array}$ & $\begin{array}{l}\text { estudo do } \\
\text { ser } \\
\text { humano }\end{array}$ & $\begin{array}{c}\text { função } \\
\text { assisten- } \\
\text { cialista }\end{array}$ & $\begin{array}{l}\text { promo- } \\
\text { ver } \\
\text { saúde }\end{array}$ & outros & branco \\
\hline Enfermagem 7ㅇ p. & (23) & 6 & 10 & 2 & 1 & 2 & 0 & 0 & 0 \\
\hline Enfermagem 60 p. & (19) & 2 & 9 & 0 & 5 & 2 & 2 & 1 & 0 \\
\hline Medicina $10^{\circ} \mathrm{p}$. & (27) & 0 & 11 & 6 & 0 & 2 & 0 & 0 & 0 \\
\hline Biologia 5o p. & (7) & 5 & 4 & 1 & 0 & 1 & 0 & 0 & 0 \\
\hline Nutrição 5으. & (16) & 4 & 6 & 1 & 0 & 0 & 0 & 0 & \\
\hline Nutrição 60 p. & (17) & 7 & 4 & 2 & 0 & 2 & 0 & 0 & 2 \\
\hline Odontologia 60 p. & (22) & 12 & 9 & 2 & 0 & 1 & 0 & 0 & 5 \\
\hline Odontologia $50 \mathrm{p}$. & (16) & 6 & 13 & 1 & 2 & 3 & 0 & 1 & 0 \\
\hline Educação física $60 \mathrm{p}$. & (22) & 16 & 7 & 0 & 1 & 2 & 0 & 1 & 2 \\
\hline Educação física $4^{\circ} \mathrm{p}$. & (22) & 8 & 9 & 0 & 4 & 3 & 0 & 1 & 0 \\
\hline Fisioterapia 60 p. n. & (32) & 9 & 14 & 4 & 2 & 4 & 1 & 0 & 2 \\
\hline Fisioterapia 60 p. m. & (38) & 17 & 20 & 4 & 1 & 2 & 0 & 0 & 0 \\
\hline Fisioterapia $4^{\circ}$ p. m. & (29) & 7 & 16 & 0 & 3 & 2 & 0 & 0 & 0 \\
\hline Fisioterapia $5^{\circ}$ p. n. & (35) & 16 & 13 & 0 & 2 & 1 & 0 & 0 & 2 \\
\hline \multirow[t]{2}{*}{ Total } & (325) & 115 & 145 & 23 & 21 & 27 & 3 & 4 & 13 \\
\hline & $\%$ & 35,4 & 44,6 & 7,1 & 6,5 & 8,3 & 0,9 & 1,2 & 4,0 \\
\hline Psicologia $7^{0}$ p. $n$. & (12) & 3 & 4 & 2 & 1 & 2 & 0 & 0 & 0 \\
\hline Psicologia $7 \underline{0}$ p.m. & (10) & 4 & 4 & 0 & 0 & 1 & 0 & 0 & 0 \\
\hline Psicologia $8^{\circ}$ p. n. & (16) & 12 & 10 & 1 & 1 & 0 & 2 & 0 & 0 \\
\hline Psicologia $8^{\circ}$ p. m. & (12) & 0 & 7 & 0 & 1 & 0 & 0 & 1 & 0 \\
\hline \multirow[t]{2}{*}{ Total } & (50) & 19 & 25 & 3 & 3 & 3 & 2 & 1 & 0 \\
\hline & $\%$ & 38,0 & 50,0 & 6,0 & 6,0 & 6,0 & 4,0 & 2,0 & 0 \\
\hline \multirow[t]{2}{*}{ Total } & (375) & 134 & 170 & 26 & 24 & 30 & 5 & 5 & 13 \\
\hline & $\%$ & 35,7 & 45,3 & 6,9 & 6,4 & 8,0 & 1,3 & 1,3 & 3,5 \\
\hline
\end{tabular}

Na categoria "objeto de estudo", fica evidenciado um alto índice percentual na subcategoria comportamento $(49,6 \%)$, tanto nos estudantes de Psicologia (44\%), como nos estudantes dos outros cursos (50,4\%). Repete-se, aqui, como na primeira categoria, uma representação individualizante e adaptativa da Psicologia, como já mostrado, de certa forma, por diversos autores (Carvalho, A. M. A., 1988; Magalhães, M. e Keller, M. S. M., 2001; Bock, A. B. M., 2000; Figueiredo, L. C. e Santi, P. L. R.,1997 e Moura, E. P. G., 1999).

Sobressai, nesse quadro, a diferença nas subcategorias mente e subjetividade entre os estudantes de Psicologia e os outros. Enquanto, para os primeiros, encontramos um percentual de $16 \%$ para mente e $24 \%$ para subjetividade, para os segundos, constata-se um percentual de $27,4 \%$ para mente e apenas 2,5\% para subjetividade. Verifica-se, também, um dado um pouco surpreendente. A subcategoria consciência apresenta um percentual de $0 \%$ nas respostas dos alunos de Psicologia; já na subcategoria inconsciente, o percentual é de $10 \%$ das respostas. Em relação aos alunos dos outros cursos, há um certo equilíbrio percentual entre essas duas subcategorias.

A não-consideração, pelos alunos de Psicologia, da consciência como objeto de estudo e a alta incidência de respostas na subcategoria comportamento parece apontar para representações acerca de seu objeto de estudo sustentadas, principalmente, por referências teóricas da Psicanálise e do Comportamentalismo. Esse dado vai de encontro ao trabalho de Bastos e Gomide (1989) com uma amostra de 2448 psicólogos de diferentes regiões do País. Os autores mostram, quanto à orientação teórico-metodológica de psicólogos, um predomínio da Psicanálise (como esperavam) e, em segundo lugar, da Análise do Comportamento. 
Kátia Botelho Diamico Praça \& Heliane Guimarães Vieites Novaes

Tabela 2: "objeto de estudo"

\begin{tabular}{|c|c|c|c|c|c|c|c|c|}
\hline & mente & Alma & $\begin{array}{l}\text { Compor- } \\
\text { tamento }\end{array}$ & $\begin{array}{l}\text { Incons- } \\
\text { ciente }\end{array}$ & $\begin{array}{l}\text { sub-cons- } \\
\text { ciência }\end{array}$ & $\begin{array}{l}\text { cons- } \\
\text { ciência }\end{array}$ & $\begin{array}{l}\text { subjeti- } \\
\text { vidade }\end{array}$ & TOTAL \\
\hline Enfermagem & 7 & & 11 & 3 & & 2 & & 23 \\
\hline Enfermagem & 2 & 1 & 9 & 2 & 2 & 3 & & 19 \\
\hline Medicina & 4 & 3 & 14 & 2 & & 1 & 3 & 27 \\
\hline Biologia & 3 & 1 & 2 & & & 1 & & 7 \\
\hline Nutrição & 5 & 2 & 5 & & 1 & 1 & 2 & 16 \\
\hline Nutrição & 4 & 1 & 10 & & 1 & 1 & & 17 \\
\hline Odontologia $\quad$ 6o $^{\mathrm{o}} \mathrm{p}$ & 5 & & 13 & 1 & 1 & 1 & 1 & 22 \\
\hline Odontologia & 4 & & 6 & 1 & 3 & & 2 & 16 \\
\hline Educação física $6^{0} \mathrm{p}$. & 11 & & 10 & & 1 & & & 22 \\
\hline Educação física $4^{\circ} \mathrm{p}$. & 3 & 1 & 15 & 1 & 1 & 1 & & 22 \\
\hline Fisioterapia $\quad 60$ p. n. & 7 & & 21 & 1 & 2 & 1 & & 32 \\
\hline Fisioterapia $\quad 6^{\mathrm{o}}$ p. m. & 10 & 2 & 21 & 1 & 2 & 2 & & 38 \\
\hline Fisioterapia $4^{\circ} \mathrm{o}$ p. m. & 13 & & 10 & 1 & 2 & 3 & & 29 \\
\hline Fisioterapia $\quad 5^{\stackrel{o}{0}}$ p. n. & 11 & 1 & 17 & & 3 & 3 & & 35 \\
\hline Total & 89 & 12 & 164 & 13 & 19 & 20 & 8 & 325 \\
\hline$\%$ & $27,4 \%$ & $3,7 \%$ & $50,4 \%$ & $4,0 \%$ & $5,8 \%$ & $6,2 \%$ & $2,5 \%$ & $100 \%$ \\
\hline Psicologia & 1 & & 7 & & & & 4 & 12 \\
\hline Psicologia $\quad 7^{0}$ p.m. & 2 & 1 & 6 & & & & 1 & 10 \\
\hline Psicologia $\quad 8^{o}$ p. n. & 2 & & 6 & 5 & & & 3 & 16 \\
\hline Psicologia $\quad 8^{o}$ p. m. & 3 & 2 & 3 & & & & 4 & 12 \\
\hline Total & 8 & 3 & 22 & 5 & & & 12 & 50 \\
\hline$\%$ & $16,0 \%$ & $6,0 \%$ & $44,0 \%$ & $10,0 \%$ & $0 \%$ & $0 \%$ & $24,0 \%$ & $100 \%$ \\
\hline Total & 97 & 15 & 186 & 18 & 19 & 20 & 20 & 375 \\
\hline
\end{tabular}

A categoria "local de trabalho" é importante, na medida em que propicia uma reflexão sobre o compromisso do profissional de Psicologia com a sociedade em que vive e trabalha. A questão que se coloca é: os serviços psicológicos continuam associados às demandas de uma elite ou há alguma mudança nesse sentido? Observando a tabela 3, encontra-se um elevado índice de respostas, principalmente nas subcategorias: hospital (93,1\%), escola $(91,2 \%)$, clínica $(88,5 \%)$ e presídio (84,8\%), ficando, porém, evidenciado um alto índice percentual na maioria das outras subcategorias, o que revela certo equilíbrio percentual. Exceção a isso pode ser observada nos itens condomínio $(17,1 \%)$, sindicatos $(29,1) \%$, igrejas $(27,5 \%)$ e centro espírita $(17,1 \%)$.

Esses dados parecem indicar uma representação mais diversificada do trabalho do psicólogo, ou seja, um reconhecimento maior da contribuição que o psicólogo pode oferecer em diversos espaços sociais, assim como um reconhecimento da interdisciplinaridade presente em sua práxis, pois sabe-se que, em estabelecimentos como hospitais e escolas, por exemplo, a idéia de um trabalho interdisciplinar é bastante presente, principalmente considerando nossa amostra.

Outro dado que deve ser ressaltado, embora apresentando um pequeno índice percentual, é a incidência de respostas que aparecem nas subcategorias igreja e centro espírita. Não causa estranheza o percentual maior nas respostas dos estudantes de Psicologia (54\% e 38\% respectivamente), já que estão mais atentos ao que acontece na área, mas o que mais importa, no entanto, é a questão de uma representação da Psicologia vinculada a crenças religiosas, a inserção de determinadas práticas por profissionais da área que podem ser seriamente questionadas, tanto em seus aspectos teórico-metodológicos, como em seus aspectos éticos.

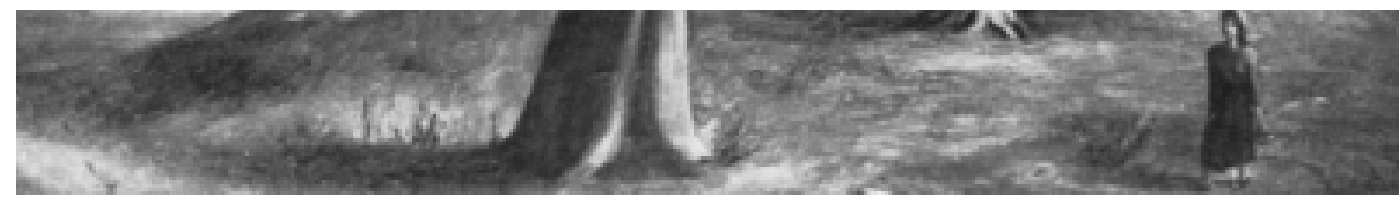


Tabela 3. "local de trabalho"

\begin{tabular}{|c|c|c|c|c|c|c|c|c|c|c|c|c|}
\hline & $\begin{array}{l}\text { condo- } \\
\text { mínio }\end{array}$ & $\begin{array}{l}\text { Com. } \\
\text { Caren- } \\
\text { te }\end{array}$ & $\begin{array}{l}\text { sindi- } \\
\text { catos }\end{array}$ & $\begin{array}{l}\text { espor- } \\
\text { te }\end{array}$ & $\begin{array}{l}\text { clíni- } \\
\text { ca }\end{array}$ & $\begin{array}{l}\text { esco- } \\
\text { La }\end{array}$ & $\begin{array}{l}\text { - hosp } \\
\text { tal }\end{array}$ & $\begin{array}{l}\text { i-com } \\
\text { sult } \\
\text { rio }\end{array}$ & $\begin{array}{c}\text { - pre- } \\
\text { ó- sí- } \\
\text { dio }\end{array}$ & $\begin{array}{l}\text { Igre- } \\
\text { Ja }\end{array}$ & $\begin{array}{c}\text { cen- } \\
\text { tro }\end{array}$ & $\begin{array}{l}\text { em- } \\
\text { pre- } \\
\text { sa }\end{array}$ \\
\hline Enfermagem $7^{\circ} \stackrel{p}{ }$. & 3 & 14 & 7 & 12 & 21 & 19 & 23 & 17 & 16 & 5 & 4 & 18 \\
\hline Enfermagem $\quad 6^{\circ} \mathrm{p}$ & 2 & 13 & 6 & 11 & 17 & 19 & 19 & 14 & 14 & 8 & 3 & 18 \\
\hline Medicina & 3 & 20 & 10 & 13 & 25 & 26 & 26 & 18 & 25 & 8 & 6 & 24 \\
\hline Biologia & 2 & 7 & 3 & 6 & 6 & 7 & 7 & 6 & 7 & 4 & 4 & 6 \\
\hline Nutrição & 2 & 9 & 4 & 10 & 11 & 11 & 11 & 11 & 10 & 4 & 5 & 11 \\
\hline Nutrição & 1 & 10 & 2 & 9 & 14 & 14 & 15 & 15 & 14 & 2 & 1 & 12 \\
\hline Odontologia $\quad 6 \mathbf{0}$. & 2 & 15 & 3 & 17 & 17 & 19 & 21 & 19 & 19 & 6 & 2 & 18 \\
\hline Odontologia $\quad 5 \mathrm{o}$ p. & 4 & 13 & 7 & 14 & 14 & 16 & 16 & 14 & 15 & 7 & 4 & 14 \\
\hline Educação física 6o $p$ & 4 & 15 & 5 & 21 & 21 & 20 & 21 & 20 & 17 & 5 & 4 & 18 \\
\hline Educação física $4^{\circ} \mathrm{p}$ & 4 & 13 & 4 & 18 & 18 & 19 & 16 & 18 & 18 & 4 & 2 & 20 \\
\hline Fisioterapia $6^{0}$ p. n. & 2 & 24 & 10 & 26 & 31 & 29 & 30 & 27 & 28 & 9 & 5 & 29 \\
\hline Fisioterapia $6 \mathbf{0}$ p. m. & 3 & 21 & 6 & 28 & 30 & 29 & 30 & 25 & 29 & 7 & 1 & 27 \\
\hline Fisioterapia 4 p. m. & 0 & 24 & 6 & 17 & 29 & 29 & 29 & 26 & 26 & 2 & 0 & 22 \\
\hline Fisioterapia $5 \underline{0}$ p. n. & 3 & 28 & 7 & 23 & 28 & 35 & 35 & 31 & 31 & 5 & 4 & 30 \\
\hline Total & 35 & 226 & 80 & 225 & 282 & 292 & 299 & 261 & 269 & 76 & 45 & 267 \\
\hline$\%$ & 10,8 & 69,5 & 24,6 & 69,2 & 86,8 & 89,8 & 392,0 & 80,3 & 82,8 & 23,4 & 13,9 & 82,2 \\
\hline Psicologia $\quad 70$ p. n. & 8 & 12 & 10 & 12 & 12 & 12 & 12 & 12 & 12 & 8 & 5 & 12 \\
\hline Psicologia 70 p.m. & 5 & 10 & 5 & 10 & 10 & 10 & 10 & 10 & 10 & 5 & 2 & 10 \\
\hline Psicologia $\quad 8^{o}$ p. n. & 8 & 16 & 9 & 16 & 16 & 16 & 16 & 16 & 16 & 10 & 9 & 16 \\
\hline Psicologia $\quad 8^{\circ}$ p. m. & 8 & 11 & 5 & 12 & 12 & 12 & 12 & 11 & 11 & 4 & 3 & 12 \\
\hline Total & 29 & 49 & 29 & 50 & 50 & 50 & 50 & 49 & 49 & 27 & 19 & 50 \\
\hline$\%$ & 58,0 & 98,0 & 58,0 & 100 & 100 & 100 & 100 & 98,0 & 98,0 & 54,0 & 38,0 & 100 \\
\hline Total & 64 & 275 & 109 & 275 & 332 & 342 & 349 & 310 & 318 & 103 & 64 & 317 \\
\hline$\%$ & 17,1 & 73,3 & 29,1 & 73,3 & 88,5 & 91,2 & 293,1 & 82,7 & 84,8 & 27,5 & 17,1 & 84,5 \\
\hline
\end{tabular}

A categoria "objetivo profissional", revela alguns dados curiosos. O maior índice percentual encontra-se na subcategoria melhorar a qualidade de vida $(44,2 \%)$. Constata-se, também, nessa tabela, que, para os estudantes dos outros cursos, o item ajudar as pessoas (24,3\%) aparece em segundo lugar; já para os estudantes de Psicologia, aparece promoção de saúde (34\%). Pode-se inferir, porém,que essa representação estaria muito mais associada à idéia de melhoria de qualidade de vida no sentido de assistencialismo, como surge na primeira categoria (caracterização da Psicologia), naquela visão individualizante do outro, do que à qualidade de vida das pessoas num sentido de conscientização, de cidadania, mais voltada para a coletividade, para trocas intersubjetivas. Essa suposição também encontra apoio se levarmos em conta a categoria "objeto de estudo", pois cabe aqui a pergunta: O psicólogo melhora a qualidade de vida a partir do trabalho que incide sobre o comportamento?

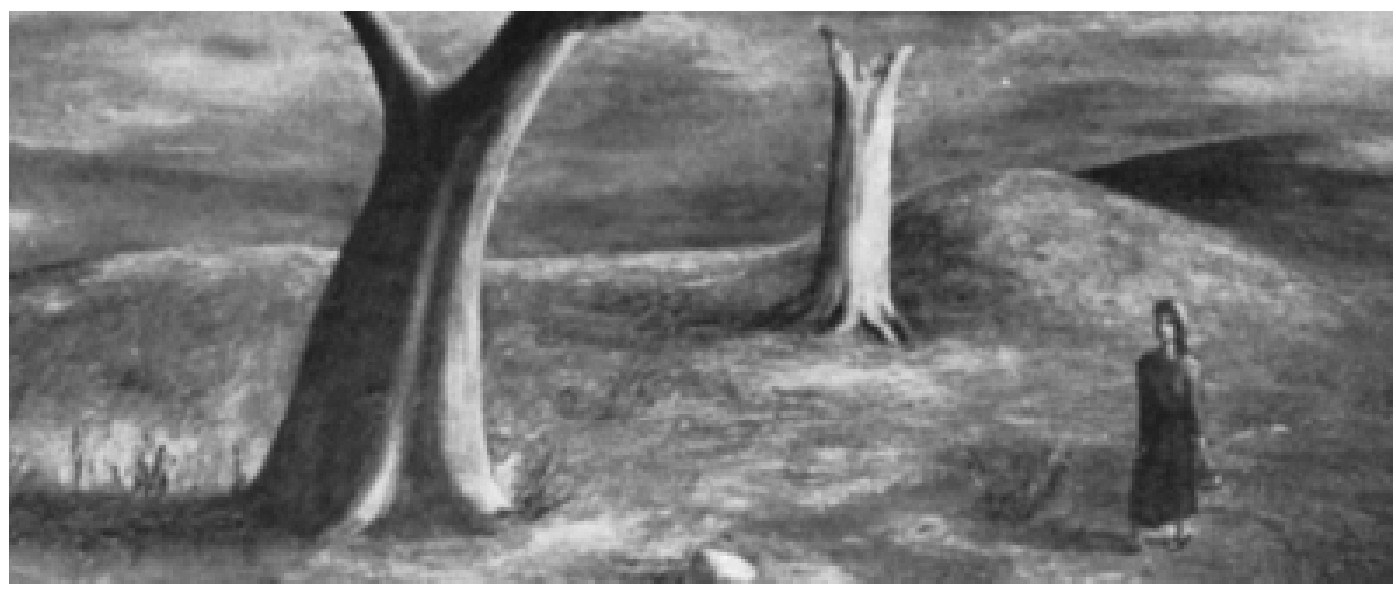


Kátia Botelho Diamico Praça \& Heliane Guimarães Vieites Novaes

Tabela 4: "objetivo profissional"

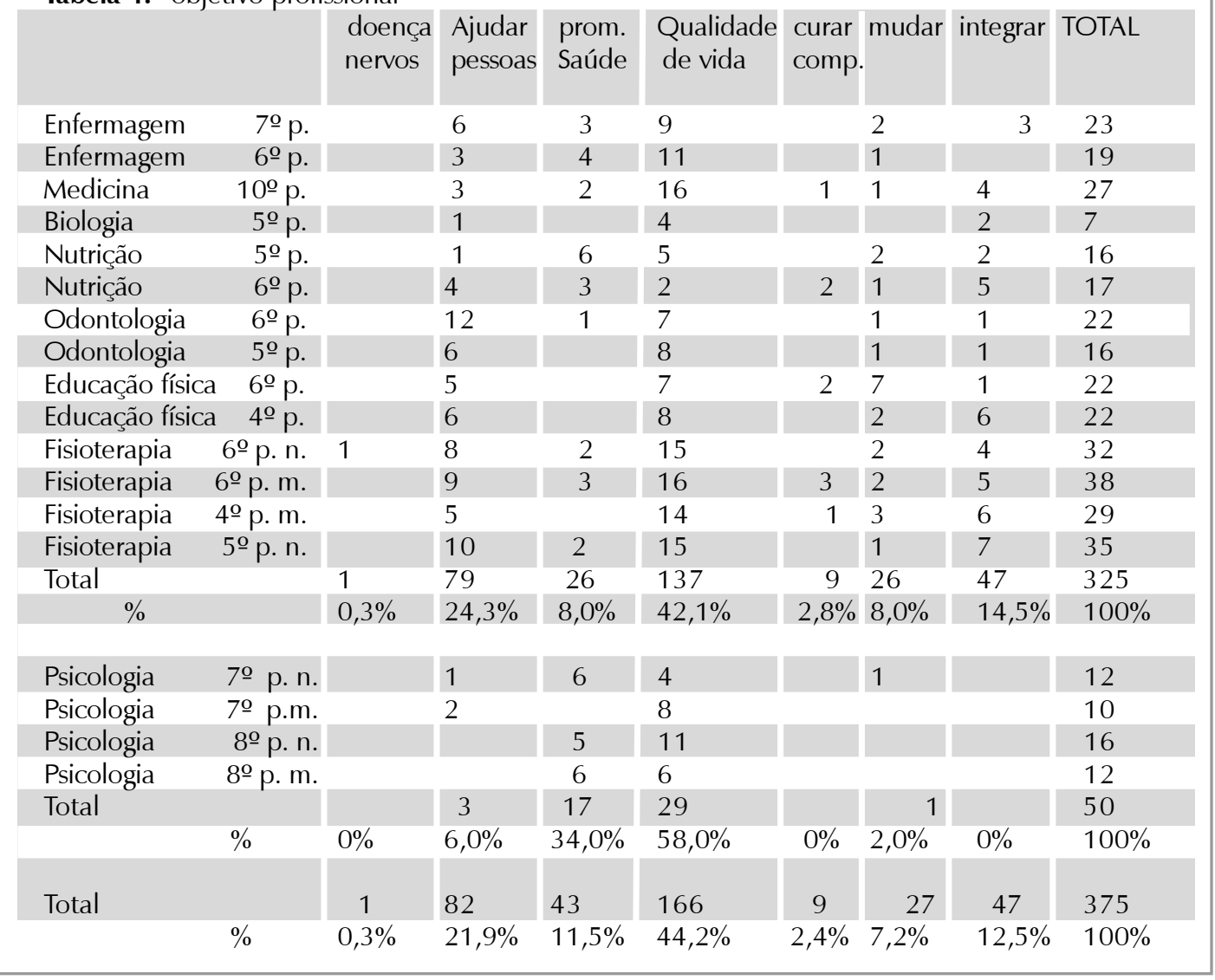

Um dado que, cabe ressaltar, embora apresente um índice

percentual relativamente pequeno, é a representação da subcategoria terapia de vidas passadas $(33,3 \%)$ como instrumento do psicólogo, o que mostra um certo desconhecimento e certa confusão do que seja uma intervenção psicológica.
A tabela 5, referente à categoria "instrumento do psicólogo", revela altos índices percentuais em instrumentos reconhecidos como psicológicos: ouvir $(89,3 \%)$, entrevistas $(87,2 \%)$, testes $(87,2 \%)$ e dinâmica de grupo $(84,5 \%)$.

Um dado que, cabe ressaltar, embora apresente um índice percentual relativamente pequeno, é a representação da subcategoria terapia de vidas passadas (33,3\%) como instrumento do psicólogo, o que mostra um certo desconhecimento e certa confusão do que seja uma intervenção psicológica.

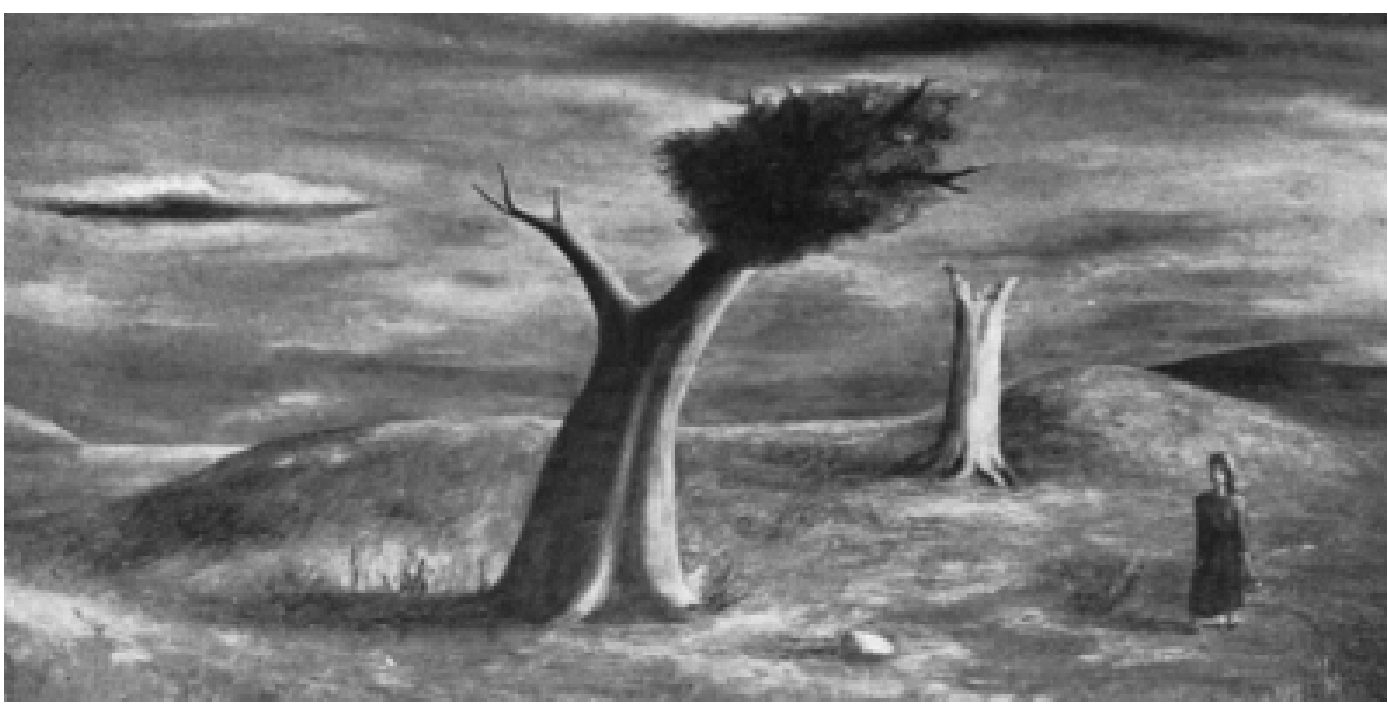




\begin{tabular}{|c|c|c|c|c|c|c|c|c|c|c|}
\hline & $\begin{array}{l}\text { medi- } \\
\text { cação }\end{array}$ & $\begin{array}{l}\text { entre- } \\
\text { vistas }\end{array}$ & $\begin{array}{l}\text { dinâ- } \\
\text { mica }\end{array}$ & $\begin{array}{l}\text { cris- } \\
\text { tais }\end{array}$ & brinq. & testes & $\begin{array}{l}\text { mapa } \\
\text { astral }\end{array}$ & Florais & ouvir & Terapia VP \\
\hline Enfermagem & 2 & 22 & 22 & & 11 & 19 & & 2 & 24 & 11 \\
\hline Enfermagem & & 17 & 17 & 3 & 6 & 14 & 1 & 3 & 15 & 5 \\
\hline Medicina & 3 & 27 & 27 & 3 & 13 & 27 & 1 & 5 & 21 & 12 \\
\hline Biologia & 3 & 7 & 6 & & 6 & 6 & & & 7 & 3 \\
\hline Nutrição & 1 & 11 & 11 & 1 & 6 & 11 & 1 & 1 & 11 & 4 \\
\hline Nutrição & 2 & 10 & 11 & & 3 & 13 & & & 13 & 4 \\
\hline Odontologia $\quad 60 \mathrm{p}$ & 15 & 19 & 19 & 1 & 7 & 15 & 1 & 2 & 20 & 7 \\
\hline Odontologia $\quad$ 5ㅇ․ & 1 & 16 & 14 & 4 & 8 & 14 & 1 & 3 & 14 & 10 \\
\hline Educação física 60 p. & 6 & 18 & 17 & 4 & 6 & 18 & 2 & 4 & 20 & 8 \\
\hline Educação física $4^{0} \mathrm{p}$. & 7 & 18 & 14 & 2 & 11 & 20 & & & 21 & 7 \\
\hline Fisioterapia $\quad 6^{0}$ p. n. & 4 & 27 & 30 & 2 & 15 & 28 & 1 & 3 & 29 & 11 \\
\hline Fisioterapia $\quad 60$ p. m. & 2 & 32 & 21 & 4 & 12 & 35 & 1 & 3 & 31 & 15 \\
\hline Fisioterapia $\quad 4^{\circ}$ p. m. & 1 & 26 & 25 & & 11 & 25 & 1 & 2 & 28 & 10 \\
\hline Fisioterapia $\quad 5^{\circ}$ p. n. & 3 & 27 & 33 & & 10 & 33 & 2 & & 32 & 14 \\
\hline Total & 65 & 277 & 267 & 24 & 125 & 278 & 12 & 28 & 286 & 121 \\
\hline$\%$ & 20,0 & 85,2 & 82,2 & 7,4 & 38,5 & 85,5 & 3,7 & 8,6 & 88,0 & 37,2 \\
\hline Psicologia $7^{0} \underline{\text { p. }}$. & & 12 & 12 & & & 9 & 11 & & 12 & 1 \\
\hline Psicologia 70 p.m. & & 10 & 10 & 1 & 11 & 10 & 1 & & 10 & 1 \\
\hline Psicologia $\quad 8^{0}$ p. n. & & 16 & 16 & & & 16 & 16 & & 15 & 1 \\
\hline Psicologia $\quad 8^{\circ}$ p. m. & & 12 & 12 & & & 12 & 12 & & 12 & 1 \\
\hline Total & & 50 & 50 & & 1 & 48 & 49 & & & 1494 \\
\hline$\%$ & 0 & 100 & 100 & & 2,0 & 96,0 & 98,0 & 0 & & $2,098,0$ \\
\hline \multicolumn{11}{|l|}{8,0} \\
\hline Total & 65 & 327 & 317 & 25 & 173 & 327 & 12 & 29 & 335 & 125 \\
\hline$\%$ & 17,3 & 87,2 & 84,5 & 6,7 & 46,1 & 87,2 & 3,2 & 7,7 & 89,3 & 33,3 \\
\hline
\end{tabular}

Na categoria "características do psicólogo", o profissional de Psicologia é representado principalmente como observador $(85,6 \%)$, equilibrado $(46,9 \%)$ e confiável $(43,2 \%)$. Importa salientar o pequeno índice percentual na subcategoria cientista $(18,2 \%)$ para os estudantes dos outros cursos. Esse fato parece implicar um não-reconhecimento do psicólogo como um cientista, o que vai de encontro a alguns resultados da categoria instrumentos do psicólogo, onde, como visto, aparecem instrumentos utilizados nas chamadas "práticas alternativas" ou " terapias de auto-ajuda". A consideração desses dados pode refletir uma questão fundamental em relação à representação que se tem da profissão no que diz respeito às práticas referidas acima.

Figueiredo já mostrou a tendência, que cresce significativamente, aumentando seu mercado, das terapias de "auto-ajuda" e que são associadas à Psicologia. Como diz o autor, "... numa mistura de concepções do senso comum ou baseadas em teorias psicológicas, em pressupostos humanistas sobre a liberdade do homem e num estilo de administração empresarial, nitidamente comportamentalista..."(1997, p.87).

Também Rolnik chama atenção para as "drogas" oferecidas no mercado em tempos de globalização: "...há ainda a droga oferecida pela literatura de "auto-ajuda"...essa categoria inclui a literatura esotérica, o boom evangélico e as terapias que prometem eliminar o desassossego, entre as quais a neurolinguística, programação behaviorista de última geração"(2000, p.2).

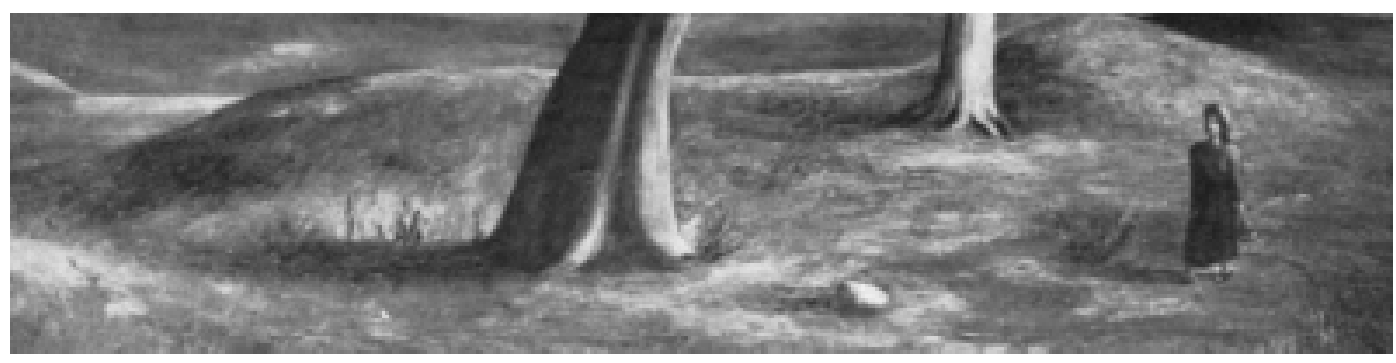


Kátia Botelho Diamico Praça \& Heliane Guimarães Vieites Novaes

\begin{tabular}{|c|c|c|c|c|c|c|c|c|c|c|}
\hline & $\begin{array}{l}\text { cien- } \\
\text { tista }\end{array}$ & $\begin{array}{l}\text { observa } \\
\text { dor }\end{array}$ & $\begin{array}{l}\text { manipu- } \\
\text { lador }\end{array}$ & $\begin{array}{l}\text { hones } \\
\text { to }\end{array}$ & $\begin{array}{l}\text { malu- } \\
\text { co }\end{array}$ & $\begin{array}{l}\text { char- } \\
\text { latão }\end{array}$ & $\begin{array}{l}\text { confiá- } \\
\text { vel }\end{array}$ & culto & $\begin{array}{l}\text { equili } \\
\text { brado }\end{array}$ & $\begin{array}{l}\text { Proble- } \\
\text { Mático }\end{array}$ \\
\hline Enfermagem $\quad 7^{0} \mathrm{p}$. & 4 & 22 & & 7 & 3 & & 14 & 8 & 7 & 2 \\
\hline Enfermagem $\quad 6^{0} \mathrm{p}$ & 2 & 17 & 2 & 1 & & & 8 & 3 & 5 & \\
\hline Medicina $\quad 10^{\circ} \mathrm{p}$. & 2 & 26 & 6 & 5 & 1 & & 1 & 5 & 14 & 2 \\
\hline Biologia & 4 & 4 & 1 & 1 & & & 1 & 1 & 4 & \\
\hline Nutrição & 4 & 10 & & & & & 3 & 3 & 4 & \\
\hline Nutrição & 3 & 13 & & 4 & & 1 & 5 & 4 & 6 & \\
\hline Odontologia $\quad 60 \mathrm{p}$ & 1 & 19 & 4 & 5 & 3 & & 11 & 2 & 11 & 3 \\
\hline Odontologia 5o p. & 6 & 15 & 4 & & & & 9 & 3 & 7 & 1 \\
\hline Educação física $6^{0}$ p. & 2 & 19 & 2 & 5 & 1 & & 8 & 6 & 18 & 1 \\
\hline Educação física $4^{\circ} \stackrel{0}{p}$. & 4 & 18 & 3 & 7 & 1 & & 9 & 6 & 9 & 2 \\
\hline Fisioterapia $\quad 6^{0}$ p. n. & 6 & 28 & 1 & 5 & 4 & & 14 & 8 & 13 & \\
\hline Fisioterapia $6^{o}$ p. m. & 3 & 29 & 4 & 11 & 5 & 1 & 16 & 7 & 19 & 2 \\
\hline Fisioterapia $4^{\circ}$ p. m. & 7 & 25 & 4 & 7 & 2 & & 12 & 4 & 12 & 4 \\
\hline Fisioterapia $\quad 5^{\mathrm{o}}$ p. n. & 11 & 30 & 3 & 10 & 1 & & 13 & 8 & 15 & 1 \\
\hline Total & 59 & 275 & 30 & 72 & 21 & 2 & 124 & 68 & 144 & 18 \\
\hline$\%$ & 18,2 & 84,6 & 92,2 & 22,2 & 6,5 & 0,6 & 38,1 & 20,9 & 44,3 & 5,5 \\
\hline Psicologia & 7 & 11 & & 6 & & & 10 & 5 & 8 & \\
\hline Psicologia & 5 & 9 & 5 & & & 6 & 7 & 5 & & \\
\hline Psicologia & 9 & 14 & 1 & 9 & & & 12 & 6 & 13 & 1 \\
\hline Psicologia & 9 & 12 & 8 & & & 1 & 10 & 10 & 6 & \\
\hline Total & 30 & 46 & 1 & 30 & & 1 & 38 & 28 & 32 & 1 \\
\hline$\%$ & 60,0 & 92,0 & 2,0 & 60,0 & 2,0 & 76,0 & 56,0 & 64,0 & 2,0 & \\
\hline Total & 89 & 321 & 31 & 102 & 21 & 3 & 162 & 96 & 176 & 19 \\
\hline$\%$ & 23,7 & 85,6 & 8,3 & 27,2 & 5,6 & 0,8 & 43,2 & 25,6 & 46,9 & 5,1 \\
\hline
\end{tabular}


Kátia Botelho Diamico Praça \& Heliane Guimarães Vieites Novaes

\begin{tabular}{|c|c|c|c|c|c|c|}
\hline & & SIM & NÃO & TALVEZ & BRANCO & TOTAL \\
\hline Enfermagem & $7^{\mathrm{o}} \mathrm{p}$. & 20 & 3 & - & - & 23 \\
\hline Enfermagem & 6o $\mathrm{p}$ & 16 & 3 & - & - & 19 \\
\hline Medicina & $10^{\circ} \mathrm{p}$. & 20 & 6 & - & 1 & 27 \\
\hline Biologia & $5^{o} \mathrm{p}$ & 5 & 2 & - & - & 7 \\
\hline Nutrição & $5^{0} \mathrm{p}$. & 13 & 2 & - & 1 & 16 \\
\hline Nutrição & $6^{0} \mathrm{p}$. & 13 & 4 & - & - & 17 \\
\hline Odontologia & $6^{\mathrm{o}} \mathrm{p}$ & 13 & 8 & - & 1 & 22 \\
\hline Odontologia & $5^{\mathrm{o}} \mathrm{p}$. & 10 & 5 & 1 & - & 16 \\
\hline Educação física & 60 p. & 14 & 8 & - & - & 22 \\
\hline Educação física & 40 p. & 12 & 9 & 1 & - & 22 \\
\hline Fisioterapia & $6^{\mathrm{o}}$ p. n. & 26 & 5 & - & 1 & 32 \\
\hline Fisioterapia & $6^{0}$ p. m. & 25 & 13 & - & - & 38 \\
\hline Fisioterapia & $4^{o}$ p. m. & 19 & 9 & - & 1 & 29 \\
\hline Fisioterapia & 5o p. n. & 28 & 3 & - & 4 & 35 \\
\hline Total & & 234 & 80 & 2 & 9 & 325 \\
\hline$\%$ & & $72,0 \%$ & $24,6 \%$ & $0,6 \%$ & $2,8 \%$ & $100 \%$ \\
\hline Psicologia & $7^{\mathrm{o}}$ p. n. & 11 & 1 & - & - & 12 \\
\hline Psicologia & $7^{\mathrm{o}}$ p.m. & 9 & 1 & - & - & 10 \\
\hline Psicologia & $8^{o}$ p. n. & 15 & 1 & - & - & 16 \\
\hline Psicologia & $8^{o}$ p. m. & 12 & - & - & - & 12 \\
\hline Total & & 47 & 3 & - & - & 50 \\
\hline$\%$ & & $94,0 \%$ & $6,0 \%$ & $0 \%$ & $0 \%$ & $100 \%$ \\
\hline Total & & 281 & 83 & 2 & 9 & 375 \\
\hline$\%$ & & $74,9 \%$ & $22,2 \%$ & $0,5 \%$ & $2,4 \%$ & $100 \%$ \\
\hline
\end{tabular}

A última categoria analisada ,"imagem da Psicologia e do psicólogo" apresenta alguns dados curiosos. Inicialmente, surge a representação da Psicologia como saúde, com uma incidência de respostas bem maior nos estudantes de Psicologia (96\%) do que nos de outros cursos (56,9\%). Pode-se atribuir esse fato, em parte, à própria formação dos estudantes de Psicologia no curso de graduação. A subcategoria de médico, psicólogo e louco todo mundo tem um pouco mostra um índice percentual de 37,9\% para os estudantes de outros cursos e, para os de Psicologia, 14\%. Considerando que, nessa subcategoria, está presente a representação de que o psicólogo é maluco, vista a equiparação entre psicólogo e louco, surge uma contradição em relação aos dados encontrados na categoria "características do psicólogo". Cabe relembrar que, lá, o profissional de Psicologia é visto como observador, equilibrado e confiável.

Outro dado que, embora com baixa incidência de respostas, vale ressaltar, é a subcategoria tenho amigos, com percentual de 12,93\% para estudantes de outros cursos, o que parece implicar uma representação do psicólogo como amigo. Surpreende, nessa tabela, o índice percentual de 18\% na subcategoria quem faz psicoterapia não tem o que fazer, para estudantes da área. Significa uma não-credibilidade na profissão que almejam? Uma representação da Psicologia como um saber-fazer que nada serve?

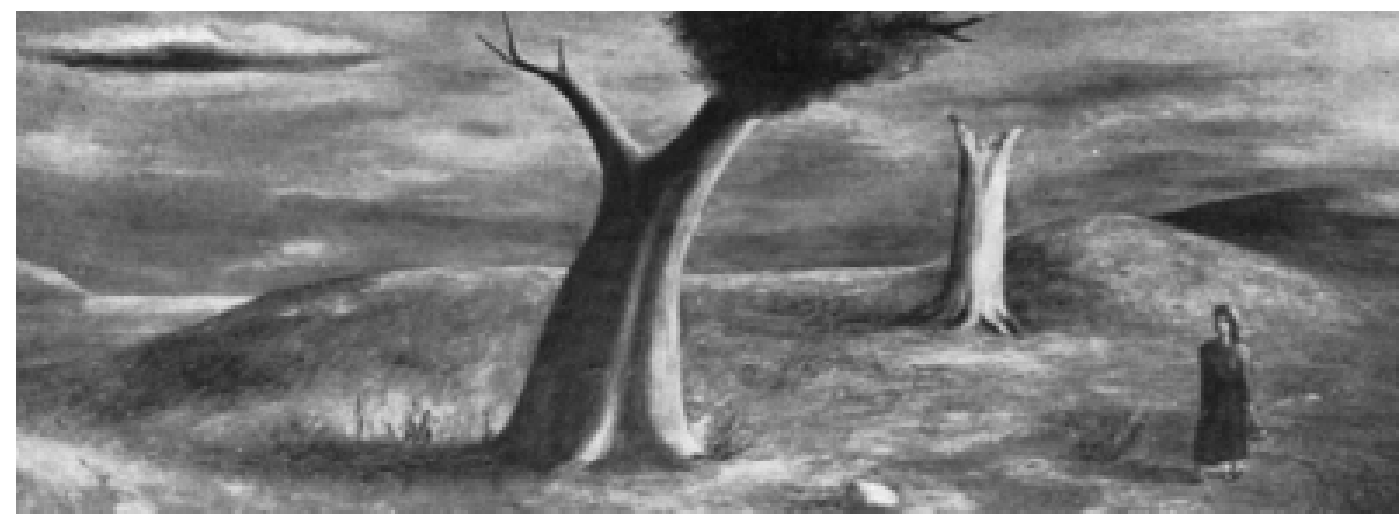




\begin{tabular}{|c|c|c|c|c|c|c|c|c|c|}
\hline & & $\begin{array}{l}\text { tenho } \\
\text { amigo }\end{array}$ & $\begin{array}{l}\text { psi é } \\
\text { maluco }\end{array}$ & $\begin{array}{l}\text { de médico } \\
\text { e louco }\end{array}$ & $\begin{array}{l}\text { psicologé } \\
\text { é saúde }\end{array}$ & só rico & $\begin{array}{l}\text { é para } \\
\text { mulher }\end{array}$ & $\begin{array}{l}\text { é supér- } \\
\text { fluo }\end{array}$ & $\begin{array}{l}\text { - não tem } \\
\text { q. fazer }\end{array}$ \\
\hline Enfermagem & $7^{\circ} \mathrm{p}$ & 2 & 4 & 18 & 2 & & & & 1 \\
\hline Enfermagem & $6^{0} \mathrm{p}$ & 1 & 4 & 4 & 9 & 2 & & 1 & \\
\hline Medicina & $10^{\circ} \mathrm{p}$. & 4 & & 12 & 9 & 10 & 1 & & 1 \\
\hline Biologia & $5^{\mathrm{o}} \mathrm{p}$. & & & 3 & 5 & 1 & & 1 & \\
\hline Nutrição & $5^{0} \mathrm{p}$. & & & 2 & 10 & 1 & & & \\
\hline Nutrição & $60 \mathrm{p}$. & 1 & & 7 & 8 & 1 & & & \\
\hline Odontologia & $60 \mathrm{p}$. & 2 & 1 & 6 & 13 & & & & \\
\hline Odontologia & $50 \mathrm{p}$. & 2 & & 3 & 9 & 3 & & & \\
\hline Educação física & a $6^{\circ} p$. & 3 & 1 & 10 & 10 & 3 & & 3 & 2 \\
\hline Educacão física & $4 \stackrel{0}{p}$. & 9 & 1 & 13 & 6 & 5 & & 1 & 1 \\
\hline Fisioterapia & $6^{o}$ p.n. & 3 & 2 & 17 & 17 & 1 & 1 & & 1 \\
\hline Fisioterapia & $6^{0}$ p.m. & 5 & & 14 & 27 & 2 & & & \\
\hline Fisioterapia & 4o p.m. & 5 & 3 & 14 & 19 & 1 & & 2 & 1 \\
\hline Fisioterapia & 5o p.n. & 3 & 1 & 14 & 25 & 4 & 1 & 1 & \\
\hline Total & & 40 & 13 & 123 & 185 & 36 & 3 & 9 & 7 \\
\hline$\%$ & & $12,3 \%$ & $4,0 \%$ & $37,9 \%$ & $56,9 \%$ & $11,1 \%$ & o $0,9 \%$ & 2,8 & $2,2 \%$ \\
\hline Psicologia & $7^{\mathrm{o}}$ p. n. & & & 1 & 11 & 1 & & & 8 \\
\hline Psicologia & 7o p.m. & & & & 10 & & & & \\
\hline Psicologia & $8^{o}$ p. n. & & 3 & 16 & & & & & 1 \\
\hline \multirow[t]{2}{*}{ Psicologia } & $8^{o}$ p. m. & & 3 & 11 & & & & & Total \\
\hline & & & 7 & 48 & 1 & & & & 9 \\
\hline$\%$ & & $0 \%$ & $0 \%$ & $14,0 \%$ & $96,0 \%$ & $2,0 \%$ & $0 \%$ & & $18,0 \%$ \\
\hline Total & & 40 & 13 & 130 & 223 & 37 & 3 & 9 & 16 \\
\hline$\%$ & & $10,7 \%$ & $3,5 \%$ & $34,7 \%$ & $59,5 \%$ & $9,9 \%$ & $0,8 \%$ & $2,4 \%$ & $4,3 \%$ \\
\hline
\end{tabular}

\section{Conclusão}

Visto que as representações sociais refletem a cultura e a sociedade na qual o sujeito está inserido, cabe, aqui, colocar em questão a própria Psicologia, já que ela é um dos objetos de nossa cultura. Nesse sentido, consideramos principalmente três aspectos importantes para reflexão: uma perspectiva liberal da Psicologia enquanto cultura, a formação do psicólogo e a responsabilidade ética e social do psicólogo.

Considerando que as explicações dadas a determinado objeto social possuem lógica própria, baseadas em informações e julgamentos valorativos, pode-se afirmar, concordando com Figueiredo, que, " ao serem incorporadas à vida quotidiana de algumas camadas da população, "as psicologias" convertem-se, quase sempre, numa visão de mundo altamente subjetivista e individualista" (1997, p.87), visto encontrar-se essa visão na própria emergência da Psicologia como ciência.

Ao que parece, tal perspectiva encontra-se neste estudo. Essa representação da Psicologia vinculase, historicamente, ao pensamento liberal, onde o homem é pensado como ser livre e autônomo, e as experiências subjetivas são vistas de forma individualizante, excluindo as condições sociais, históricas e culturais presentes nessas experiências.

Surge, então, nesse cenário, um terreno fértil para uma psicologização da vida quotidiana e um pensamento acrítico em relação ao contexto histórico-social. Parece que o psicólogo é representado como um profissional que nada tem a ver com a dimensão sociohistórica da sociedade em que vive e trabalha.

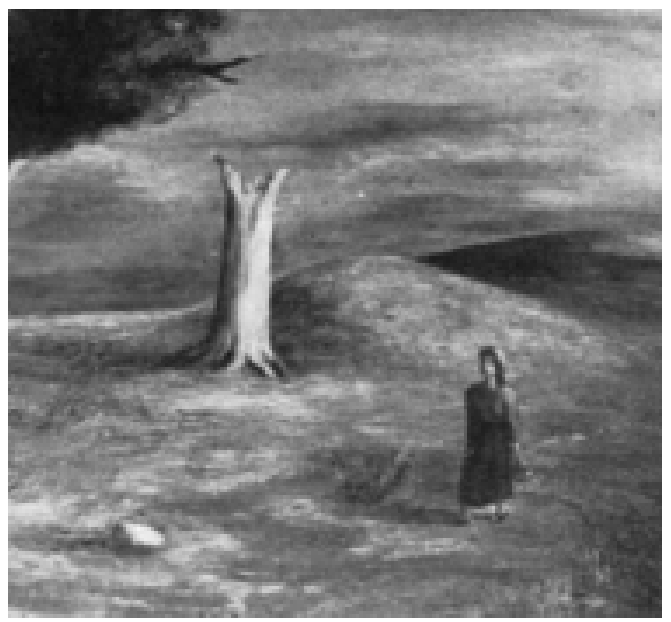

"...ao serem incorporadas à vida quotidiana de algumas camadas da população, "as psicologias" convertem-se, quase sempre, numa visão de mundo altamente subjetivista e individualista".

Figueiredo 
Kátia Botelho Diamico Praça \& Heliane Guimarães Vieites Novaes

Dessa forma, constata-se que inexiste uma reflexão sobre a responsabilidade ética do psicólogo no seu trabalho, sobre a sua função social (sim, pois não cabe mais a negação ou rejeição da idéia de que, como ser sociohistórico, qualquer atividade do homem é uma atividade política).

Admitindo que o fazer psicológico é efeito, em grande parte, da formação que o profissional recebe, pergunta-se: durante sua formação, é dado ao futuro psicólogo oportunidades de se perguntar sobre a vertente política de sua profissão e sobre seu lugar ético?
Aqui, torna-se fundamental pensar que, à medida que a Psicologia e os psicólogos são ainda representados como agentes de adequação e integração social, não há espaço para a ética, pois, dessa forma, o sujeito torna-se objeto. Cabe ao psicólogo (e também aos estudantes) interrogar-se constantemente sobre seu saber-fazer de forma crítica. Agente de transformação ou agente de adequação?

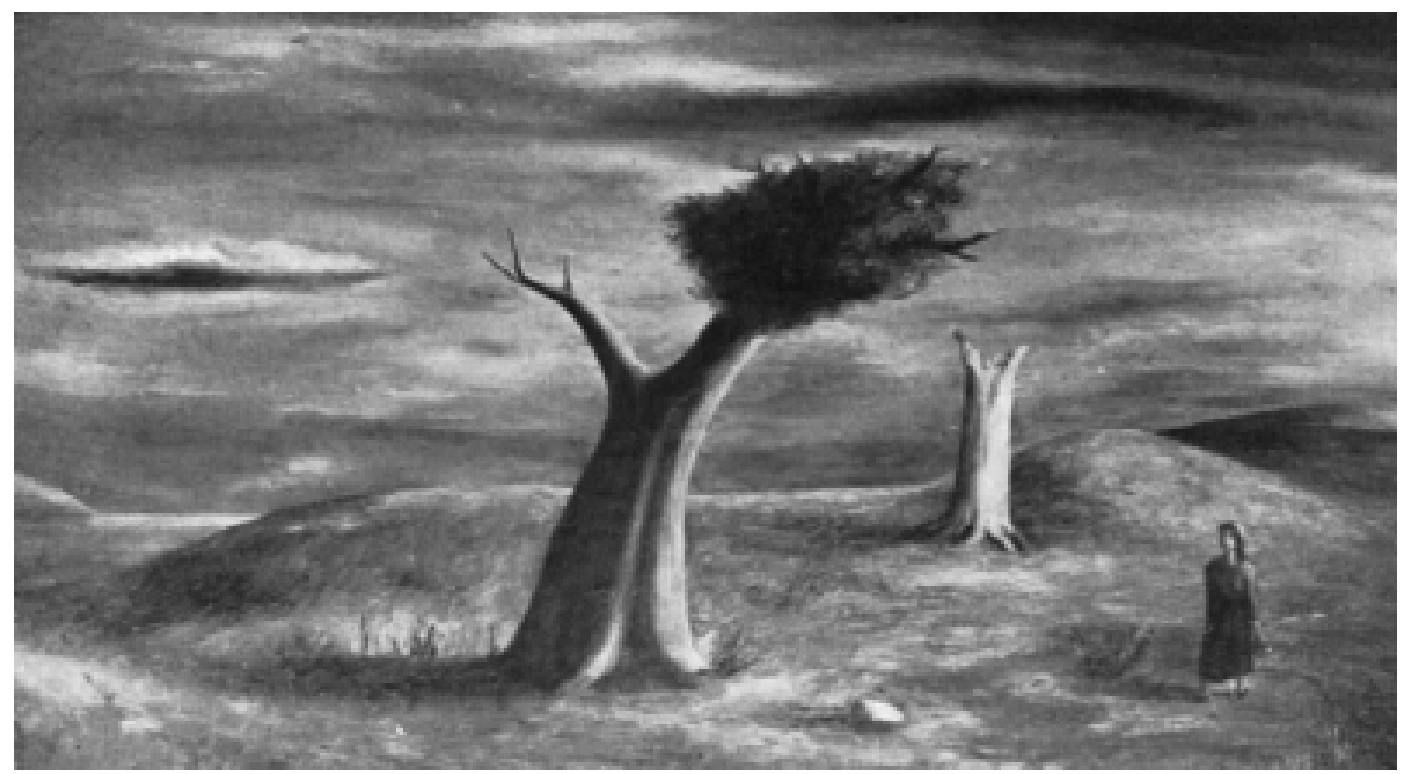


Kátia Botelho Diamico Praça \& Heliane Guimarães Vieites Novaes Universidade Gama Filho - Rua Conde de Bonfim, 838/ 1404 - Tijuca- Rio de Janeiro. Cep 20530-002. E-mail:helianegvn@ig.com.br.

BASTOS, A. V. B. Áreas de Atuação: em Questão o Nosso Modelo Profissional. Quem éo Psicólogo Brasileiro. São Paulo: Edicon, 1988.

BASTOS, A. V. B. e GOMIDE, A. I. C. O Psicólogo Brasileiro: sua Atuação e Formação Profissional. Psicologia: Ciência e Profissão. Brasilia, v. 9 n. 2, 1989, pp.6-15.

BARDIN, L.. Análise de Conteúdo Lisboa: Edições 70, 1977.

BOCK, A. B. M. As Influências do Barão de Munchhausen na Psicologia da Educação. Psicologia e Educação- Desafios Teórico-práticos. São Paulo: Casa do Psicólogo, 2000.

BOCK, A. B. M. A Formação do Psicólogo: um Debate a Partir do Significado do Fenômeno Psicológico. Psicologia: Ciência e Profissão. Brasília, v. 17, n. 2, 1997,pp.37-42.

BRANCO, M. T. C. Que Profissional Queremos Formar? Psicologia: Ciência e Profissão. Brasilia, v. 18, n. 3, 1999, pp.28-35.

CARVALHO, A. M. A. Atuação Psicológica: uma Análise das Atividades Desempenhadas Pelos Psicólogos. In Conselho Federal de Psicologia. Quem é o Psicólogo Brasileiro. São Paulo: Edicon, 1988, pp.217-235.

CONTINI, M. L. J. Discutindo o Conceito de Promoção de Saúde no Trabalho do Psicólogo que Atua na Educação. Psicologia: Ciência e Profissão. Brasília, v. 20, n. 2, 2000, pp.46-58.

FIGUEIREDO, L. C. e SANTI, P. L. R. Psicologia uma (Nova) Introdução. São Paulo: Educ, 1997.

JOVCHELOVITCH, S. e GUARESCHI, P. Textos em Representações Sociais. Petrópolis: Vozes, 1994

IEME, M. A. S., BUSSA V. S. R. e OTTA, E. A. A Representação Social da Psicologia e do Psicólogo. Psicologia: Ciência e Profissão. Brasília, v. 9, n. 1, 1989,p

MAGALHÃES, M.; STRALIOTTO, M.; KELLER, M. S. M. e GOMES, W. B. Eu Quero Ajudar as Pessoas: A Escolha Vocacional em Psicologia. Psicologia: Ciência e Profissão. Brasília, v.21, n.ํ2, 2001, pp.10-27.

MELLO, S. L. Psicologia e Profissão em São Paulo. São Paulo: Ática, 1975.

MOSCOVICI, S. La Psicanalyse, son Image et son Public. Paris: Presse Universitaire de France, 1961.

Zahar, 1978. A Representação Social da Psicanálise. Rio de Janeiro:

The Phenomenon of Social Representations. In Farr, R. M. e Moscovici, S. (orgs). Social Representations. Cambridge: Cambridge University Press, 1981.

MOURA, E. P. G. A Psicologia (e os Psicólogos) que Temos e a Psicologia que Queremos: Reflexões a Partir das Propostas de Diretrizes Curriculares (MEC/SESU) para os Cursos de Graduação em Psicologia. Psicologia: Ciência e Profissão. v. 19, n. 2, 1999, pp.10-19.

PASQUALI, L. Condições de Trabalho do Psicólogo. In Conselho Federal de Psicologia .Queméo Psicólogo Brasileiro. São Paulo: Edicon, 1988, pp.149-162.

ROLNIK, S. Toxicômanos de Identidade. In Daniel L. (org). Cultura e Subjetividade. São Paulo: Papirus, 2000.

ROSAS, P., ROSAS, A. e XAVIER, I. P. Quantos e quem Somos. In Conselho Federal de Psicologia. Quem é o Psicólogo Brasileiro. São Paulo: Edicon, 1988, pp.32-88.

SÁ, C. P.AConstrução do Objeto de Pesquisa em Representações Sociais. Rio de Janeiro: UERJ, 1998. 